\title{
Mechanical and thermal shock properties of size graded MgO-PSZ refractory
}

\author{
Wen-Cheng J. Wei*, Yuh-Pring Lin \\ Institute of Materials Science and Engineering, National Taiwan University, Taipei, Taiwan 106, ROC
}

Received 17 February 1999; received in revised form 26 August 1999; accepted 12 September 1999

\begin{abstract}
The effects of the mixture of coarse powder with fine PSZ powder on the thermal-mechanical properties of $10 \mathrm{Mg}-\mathrm{PSZ}$ samples were studied. The size graded specimens were injection-molded using $3.5 \mathrm{~m} \% \mathrm{MgO}-\mathrm{ZrO}_{2}$ powders. The physical properties of the $\mathrm{ZrO}_{2}$ samples and five thermal shock parameters were measured and calculated. These properties included density $(\rho)$, porosity $(p)$, the ratio of $\mathrm{m} /(\mathrm{t}+\mathrm{c}+\mathrm{m})$ phase, fracture toughness $\left(K_{\mathrm{IC}}\right)$, strength $\left(\sigma_{\mathrm{f}}\right)$, Young's modulus $(E)$, shear modulus $(G)$, Poisson's ratio $(v)$, and the thermal expansion $(\alpha)$ between ambient temperature to $1100^{\circ} \mathrm{C}$. The toughness and thermal shock resistance of the PSZ are controlled by the states of porous microstructure which can be represented by a parameter (nominal largest tolerable length of defects) $a_{\mathrm{t}}$. The PSZ samples show two types of thermal shock behavior differentiated by comparing the value of $a_{\mathrm{t}}$ to the characteristic length $L_{\mathrm{f}}$ of the defects in the sintered PSZ. The states of the defects, i.e. porosity, are the microstructural evidence to explain the relationship between the thermal shock properties. (C) 2000 Elsevier Science Ltd. All rights reserved.
\end{abstract}

Keywords: Mechanical properties; Refractories; Thermal properties; Thermal shock; $\mathrm{ZrO}_{2}$

\section{Introduction}

Zirconia is a high temperature resistant material with excellent thermal insulation property currently used as a refractory, ${ }^{1}$ which is especially resistant to the corrosion caused by basic slags in the continuously casting of molten steel. However, the thermal expansion of the material is very high among structural ceramics. Those unfavorable thermomechanical properties make zirconia materials very sensitive to thermal shock.

Bullard and Cheng ${ }^{2}$ reported that a $\mathrm{ZrO}_{2}$ nozzle with a smaller grain size was easily spalled during thermal shock and the catastrophic failure of the refractory parts limits the application for long-term service. They further reported that a zirconia refractory with controlled porosity and density, and a greater consistency in texture would perform better at high temperature.

For the past two decades, zirconia has greatly improved in toughness ${ }^{3,4}$ and the strength is greatly controlled by the type and amount of monoclinic (m)

* Corresponding author at: 1 Roosevelt Road, Sec. 4, Taipei, Taiwan 106, ROC. Tel.: + 886-2-23632684; fax: +886-2-23634562.

E-mail address: wjwei@ccms.ntu.edu.tw (Wen-Cheng J. Wei). phase in the zirconia materials (TZP and PSZ). The transformation toughening occurring at an ambient temperature has made zirconia useful in several stringent applications. However, the transformation toughening is not effective at high temperatures, nor occurs in the conditions of thermal cycling. Very few high temperature applications of zirconia have emphasized the merits of the toughening effects. Alternatively, destabilization of $\mathrm{ZrO}_{2},{ }^{5,6}$ microstructural modifications ${ }^{7,8}$ or grain size optimization $^{9}$ in other ceramic systems have proven to be capable of improving thermal shock properties.

One of the microstructural modifications was reported by Lutz et al. ${ }^{7}$ on a series of ceramic composites with a duplex microstructure. The improvement of thermal shock properties can be retrieved from the crack deflection and branching using a reinforced second phase. The agglomerated $\mathrm{ZrO}_{2}$ inclusions have strengthened the neighboring matrix and undergo transformation toughening so to adsorb fracture energy. Among the cases presented, the size and distribution of the second-reinforced zirconia inclusions are the primary properties of the composite.

In our previous work, ${ }^{10}$ a series of zirconia with fine/ coarse mixtures was prepared using an injection molding 
techniques. The zirconia samples with uniform microstructures were sintered in different conditions to achieve various porous and grain structures. The designed microstructures with unique features, combined coarse grains, pores, and cracks, are desirable for a fundamental study. The samples were prepared with a similar content of $\mathrm{m}$-phase. It can differentiate the contributions of the structural factors from the phase transformation of the size-grading zirconia.

\section{Experimental}

\subsection{Materials}

Two zirconia powders and one $\mathrm{MgO}$ powder were used for the preparation of the partially stabilized zirconia (PSZ) mixture. One is the coarse powder (AQZ100, Universal Abrasives, UK) with an angular shape and in an average particle size of $60 \mu \mathrm{m}$. The AQZ powder appeared as a PSZ has a magnesia and calcia contents of 3.66 and 0.3 mass $\%$. The other is the fine powder (non-stabilized, EF-PREMIUM, Z-Tech Co., USA) in an average particle size of $1.0 \mu \mathrm{m}$, which appears as a spherical shape and mild agglomeration.

Five sets of the PSZ samples were formulated, F00F100, containing the fine EF powder from 0 to 100 mass $\%$. To keep the $\mathrm{MgO}$ content constant, $3.6 \pm 0.1$ mass $\%$, in all formulations, an $\mathrm{MgO}$ powder was used which was prepared from the calcination of a hydrolyzed magnesium carbonate powder (City Gate International Co., Ltd., ROC).

\subsection{Injection molding and sintering}

The powders were mixed with a binder system and injection molded. The details concerning kneading of the feedstocks, injection molding, solvent and thermal debindings are described in the previous paper. ${ }^{10}$ After injection-molding and debinding, the samples were sintered at the temperatures of $1450 \sim 1750^{\circ} \mathrm{C}$. The details of sintering conditions are shown in Table 1.

\subsection{Characterization}

The density of sintered samples was measured by Archimedes' method. The PSZ samples in different grinding and heat-treatment stages were tested using an X-ray diffractometer (XRD, PW1792, Philips Instrument, Netherlands). The amount of monoclinic phase in the as-sintered zirconia was determined following a quantitative XRD technique reported by Garvie et al. ${ }^{11}$

An ultrasonic instrument (DTM 12, KrautkramerBranson Co., Ltd., Germany) was used for the measurement of elastic and shear moduli, and Poisson's ratio. The velocities of transverse and longitudinal waves of $5 \mathrm{MHz}$ were measured to calculate the PSZ properties according to the ASTM standard (C1198-91).

The four-point bending test of ASTM C1161-90 was conducted for the measurement of the bending strength of PSZ samples. The single edge notched beam (SENB) method $^{12}$ was used for the measurement of the toughness of the zirconia test bars. Both tests were executed on an MTS universal testing machine (model 810, MTS Co., USA). Each data point was averaged from at least either $10\left(\sigma_{\mathrm{f}}\right.$ measurement $)$ or four $\left(K_{\mathrm{IC}}\right)$ measurements.

The thermal shock resistance of PSZ was evaluated by using the same PSZ test bars as used in the four-point bending test. The test bar was pre-heated to a specified temperature for $30 \mathrm{~min}$, then quenched in distilled water $\left(25^{\circ} \mathrm{C}\right)$. The quenched sample was dried and the retained strength of the PSZ was measured.

A scanning electron microscope (Mini-SEM, JEOL Co., Japan) was used to observe the polished and fracture

Table 1

The assigned symbol, sintering and physical properties of $10 \mathrm{Mg}-\mathrm{PSZ}$ specimens sintered in different conditions

\begin{tabular}{|c|c|c|c|c|c|c|c|c|c|c|}
\hline Symbol $^{\mathrm{a}}$ & $\begin{array}{l}\text { Range of } \\
\text { density } \\
\left(\mathrm{g} / \mathrm{cm}^{3}\right)\end{array}$ & $\begin{array}{l}\text { Sintering } \\
\text { temperature } \\
\text { and time }\end{array}$ & $\begin{array}{l}\text { Bulk } \\
\text { density } \\
\left(\mathrm{g} / \mathrm{cm}^{3}\right)\end{array}$ & $\begin{array}{l}\text { Total or } \\
\text { closed } \\
\text { porosity }(\%)\end{array}$ & $\begin{array}{l}K_{I C} \\
\left(\mathrm{MPa} \mathrm{m}^{1 / 2}\right)\end{array}$ & $\sigma_{f}(\mathrm{MPa})$ & $E(\mathrm{GPa})$ & $v$ & $\begin{array}{l}\alpha \times 10^{-6} \\
\left(\mathrm{~K}^{-1}\right)^{\mathrm{b}}\end{array}$ & $\begin{array}{l}\gamma(\mathrm{Pa} \mathrm{m}) \\
\text { or }\left(\mathrm{J} / \mathrm{m}^{2}\right)^{\mathrm{c}}\end{array}$ \\
\hline $\mathrm{F} 100 \mathrm{H}$ & 5.4 & $1700^{\circ} \mathrm{C} \times 4 \mathrm{~h}$ & 5.36 & $6.5,6.5$ & 5.40 & 441 & 213 & 0.25 & 13.7 & 64.2 \\
\hline F100M & 5.0 & $1450^{\circ} \mathrm{C} \times 1 \mathrm{~h}$ & 4.98 & $13.1,5.5$ & 3.24 & 243 & 187 & 0.14 & 11.6 & 27.5 \\
\hline $\mathrm{F} 75 \mathrm{H}$ & 5.0 & $1700^{\circ} \mathrm{C} \times 4 \mathrm{~h}$ & 4.97 & $13.3,5.8$ & 2.71 & 248 & 199 & 0.18 & 13.8 & 17.8 \\
\hline F75M & 4.6 & $1450^{\circ} \mathrm{C} \times 3 \mathrm{~h}$ & 4.65 & $18.9,0.4$ & 1.45 & 142 & 155 & 0.26 & 12.0 & 9.0 \\
\hline $\mathrm{F} 50 \mathrm{H}$ & 4.6 & $1700^{\circ} \mathrm{C} \times 4 \mathrm{~h}$ & 4.56 & $22.2,0.7$ & 4.40 & 133 & 161 & 0.19 & 14.1 & 57.9 \\
\hline F75L & 4.3 & $1450^{\circ} \mathrm{C} \times 1 \mathrm{~h}$ & 4.34 & $24.3,0.3$ & 1.18 & 137 & 124 & 0.20 & 11.9 & 9.3 \\
\hline F50M & 4.3 & $1550^{\circ} \mathrm{C} \times 1 \mathrm{~h}$ & 4.22 & $27.0,0.5$ & 2.58 & 53 & 131 & 0.19 & 12.4 & 24.5 \\
\hline F25 & 3.9 & $1700^{\circ} \mathrm{C} \times 4 \mathrm{~h}$ & 3.93 & $32.1,0.0$ & 1.39 & 67.9 & 83.6 & 0.22 & 12.9 & 11.0 \\
\hline F50L & 3.7 & $1450^{\circ} \mathrm{C} \times 1 \mathrm{~h}$ & 3.80 & $33.9,0.0$ & 1.72 & 54.6 & 85.8 & 0.21 & 12.0 & 16.5 \\
\hline F00 & 3.7 & $1700^{\circ} \mathrm{C} \times 4 \mathrm{~h}$ & 3.67 & $36.5,0.0$ & 0.92 & 42.2 & 88.7 & 0.20 & 14.0 & 4.6 \\
\hline
\end{tabular}

a $\mathrm{H}$, relatively high density; $\mathrm{M}$, medium density; L, relatively low density.

${ }^{\mathrm{b}} \alpha$ is calculated within $20 \sim 1000^{\circ} \mathrm{C}$.

c $\gamma=K_{I C}^{2}\left(1-v^{2}\right) / 2 E$. 
surfaces of the PSZ at different stages. After polishing, the specimens were etched with $48 \%$ HF solution at $20^{\circ} \mathrm{C}$ for 4 min to reveal the grain boundaries.

\section{Results}

\subsection{Density and crystalline phase}

In order to distinguish the effects of coarse/fine powder ratio on the microstructure and on the physical properties of the PSZ, six ranges of the density (from 5.4 to $3.7 \mathrm{~g} / \mathrm{cm}^{3}$ ) and 10 PSZ samples are prepared, as shown in Table 1. The porosity of the PSZ ranges from 6.5 to $36 \%$, being mostly open porosity. Only three exceptions, either F100H, F100M or F75H, had closed porosity of $6.0-5.5 \%$. In addition, there is no open porosity in $\mathrm{F} 100 \mathrm{H}$. Most of the closed pores are in the sizes 4 to $16 \mu \mathrm{m}$ located at the grain boundaries.

Because the surfaces of the sintered PSZ samples were not flat, surface machining by diamond wheel followed by heat-treatment was required. The $\mathrm{m}$-phase of the PSZ was $5 \pm 1 \%$ after sintering at $1650^{\circ} \mathrm{C}$. But the $\mathrm{m}$ phase of the F100 increases to $16 \%$ once they were ground by a diamond wheel, as shown in Fig. 1. However, the amount of m-phase would reduce to 6 or $13 \%$ when the ground samples were treated at 1400 or $1450^{\circ} \mathrm{C}$ for less than $1 \mathrm{~h}$. Moreover, the quantity of $\mathrm{m}$ phase would increase as the time of the heat treatment extended. Therefore, the samples for the following test would undergo surface grinding and heat-treatment at $1400^{\circ} \mathrm{C}$ for $2 \mathrm{~h}$ to ensure the $\mathrm{m} /(\mathrm{t}+\mathrm{m}+\mathrm{c})$ phase ratio of

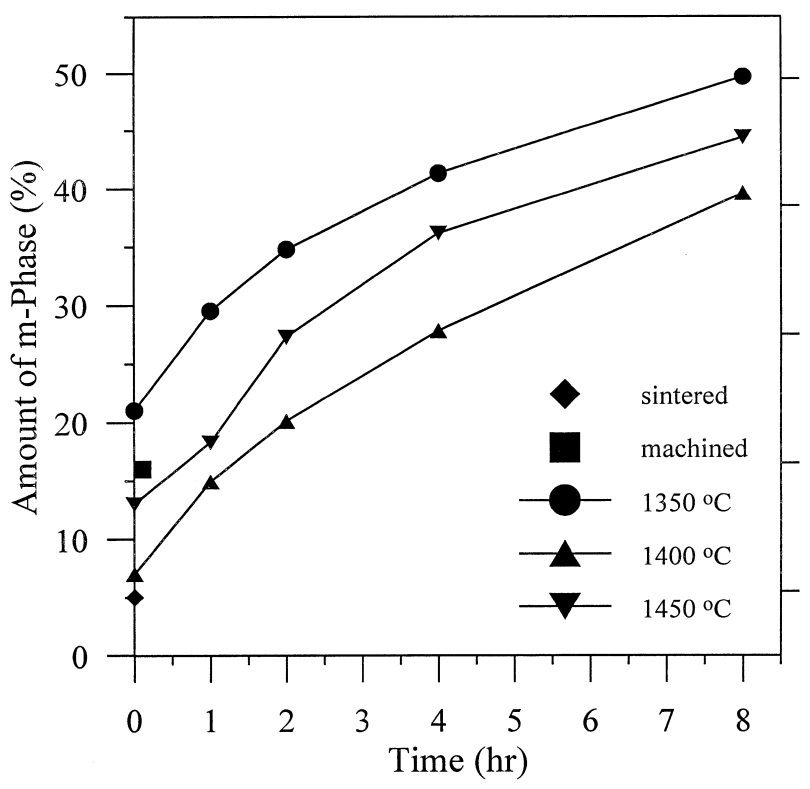

Fig. 1. The amount of m-phase of F100 PSZ sample either as-sintered, or followed diamond-wheel grinding, then heat-treated at 1350 to $1450^{\circ} \mathrm{C}$ plotted as a function of heat-treatment period. all PSZ remaining $20 \pm 2 \%$. No r-phase is found from the XRD patterns.

\subsection{Material properties of PSZ}

The elastic modulus, shear modulus and Poisson's ratio of the PSZ as a function of porosity are reported in Fig. 2. The magnitude of the elastic modulus or shear modulus decreases as the porosity increases. Two properties of 10 PSZ are plotted and fitted by semi-empirical equations. They show

$E=E_{0} \exp (-A P)$ or $G=G_{0} \exp (-B P)$

where $E_{0}$ and $G_{0}$ are the elastic and shear moduli, respectively, of the PSZ with zero porosity, and $A$ and $B$ are constants. The values of $E_{0}$ and $G_{0}$ are estimated from Fig. 2 to be $296 \mathrm{GPa}$ and $186 \mathrm{MPa}$, respectively. The elastic modulus of the best sample, F100H, $(213$ $\mathrm{GPa}$ ) is lower than the calculated $E_{0}$, but close to the value $(200 \mathrm{GPa})$ reported in the literature. ${ }^{13}$ In contrast, the Poisson's ratio values, varied from 0.14 to 0.26 , of these PSZ (Fig. 2) are rather scattered, especially for the samples with a higher density. But the values converge to 0.20 as the porosity of the PSZ is greater than $20 \%$. The variation of the ratio is also possibly limited by the capability of the ultrasonic technique. Poisson's ratio data of PSZ is not available in literature to make a comparison.

The thermal expansion data of $10 \mathrm{PSZ}$ are reported in Fig. 3, and the average CTE values are calculated in the range of $12.8 \pm 1.2 \times 10^{-6} / \mathrm{K}$. The expansion and shrinkage behaviors of six Mg-stabilized PSZ did not show the $\mathrm{t} / \mathrm{m}$ transformation above room temperature. It means that the Martensitic transformation $\left(M_{\mathrm{s}}\right)$ temperature can be measured only below room temperature. However,

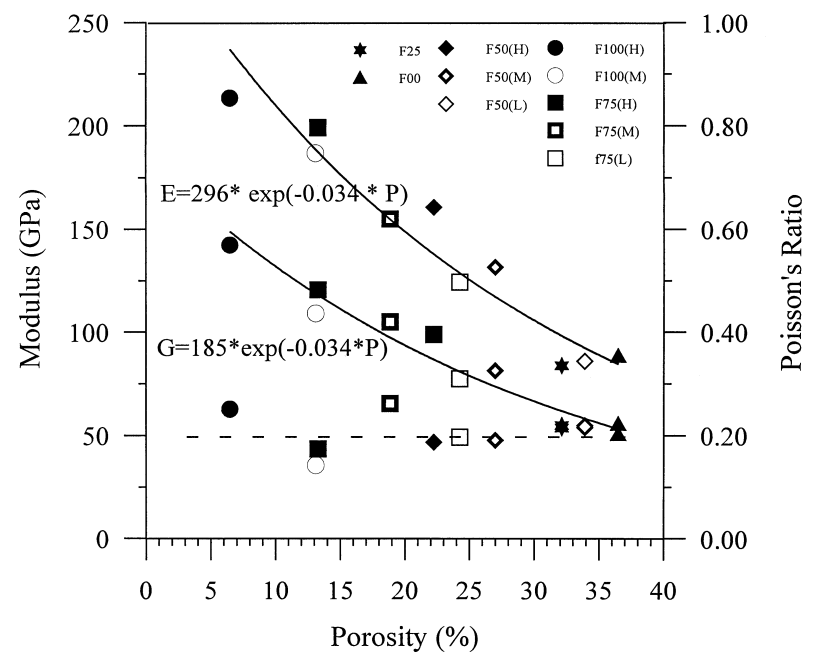

Fig. 2. Elastic modulus $(E)$, shear modulus $(G)$ and Poisson's ratio $(v)$ of the PSZ plotted as a function of porosity. 


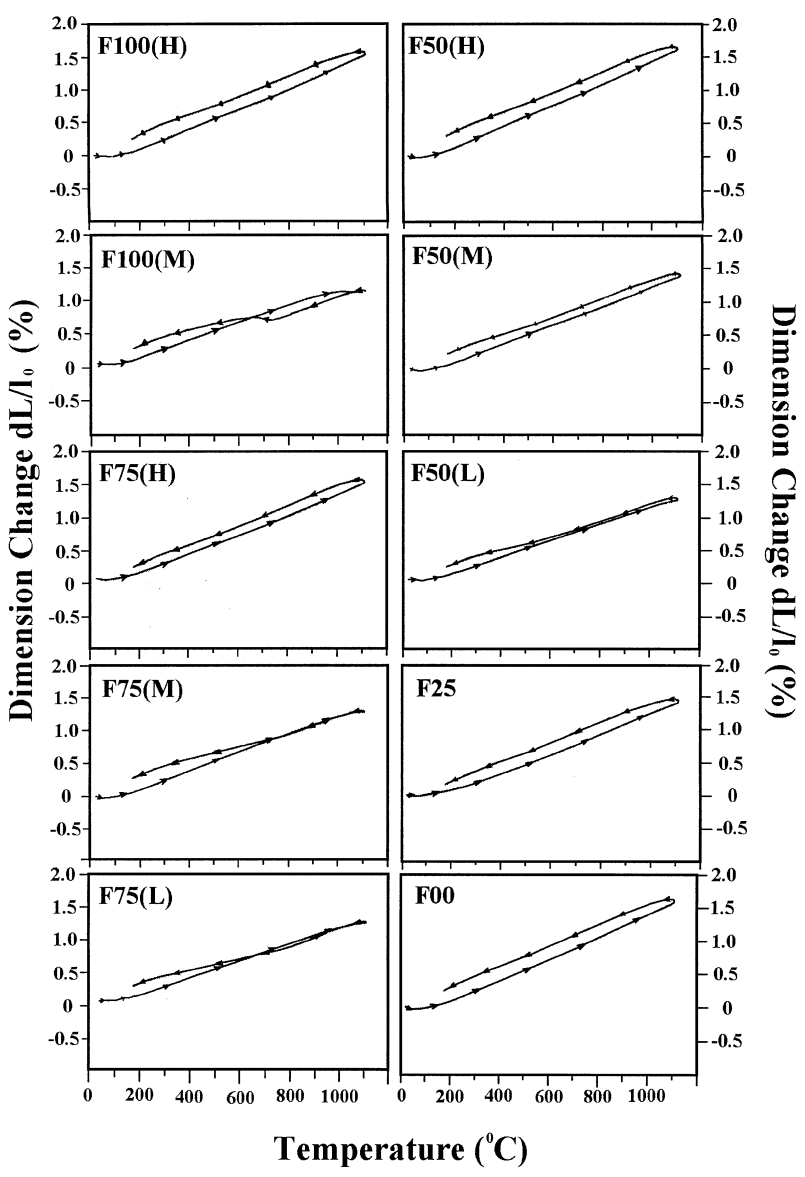

Fig. 3. Dilatometric and shrinkage curves of $10 \mathrm{PSZ}$ plotted as a function of test temperature.

four specimens, including F100M, F75M, F75L and F50L, show their $M_{\mathrm{s}}$ temperatures as high as $650^{\circ} \mathrm{C}$. Upon cooling, the linear contraction of four PSZ shows a t-to-m transformation. The phenomena are consistent for the PSZ samples with a higher fine-powder content (F100, F75 or F50) and sintered at $1450^{\circ} \mathrm{C}$ (Table 1). As long as the formulation contains more $(>25 \%)$ coarse zirconia grains (stabilized AQZ powder) and densified at $1550^{\circ} \mathrm{C}$ or higher temperatures will be stabilized and not undergo t-to-m transformation.

\subsection{Mechanical properties of PSZ at room temperature}

The fracture strength at room temperature was measured and plotted as a function of porosity of PSZ (Fig. 4). The measured strength of the PSZ ranges from 441 to $52 \mathrm{MPa}$. The data can be fitted with an empirical equation which depicts the relationship of strength $(\sigma)$ to porosity $(p)$ below

$\sigma=\sigma_{0} \exp (-C p)$

where $\sigma_{0}$ is the strength of the samples without porosity (in \%) and $C$ is a constant. The values of $\sigma_{0}$ and $C$ are

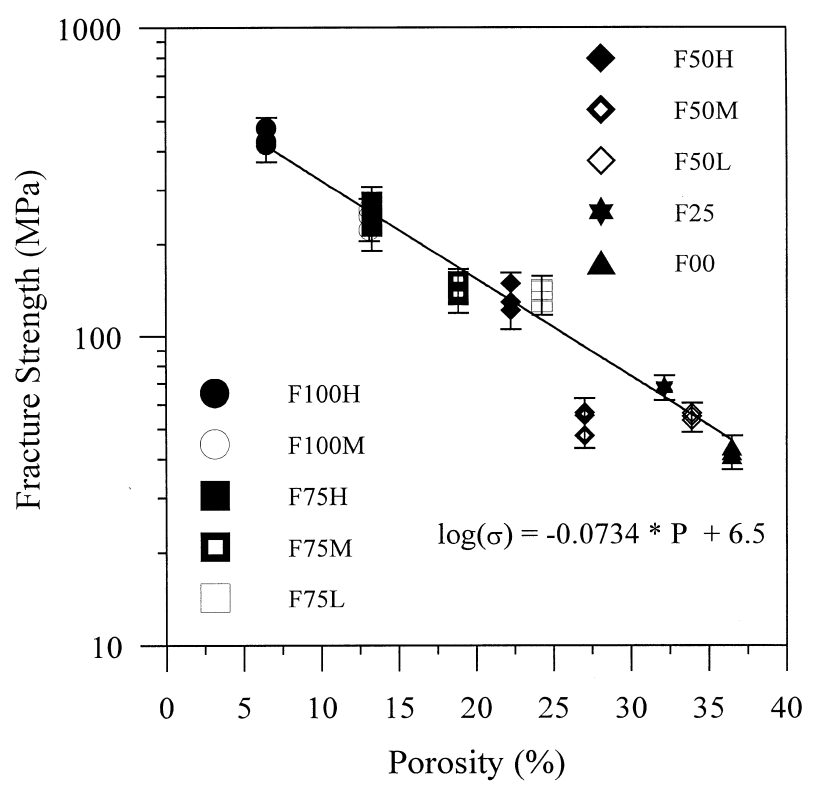

Fig. 4. Fracture strength tested at room temperature plotted as a function of the porosity of PSZ.

$665 \mathrm{MPa}$ and 0.073 , respectively. The character of the fitting line reveals that the strength of the PSZ can be an exponential function of porosity, except for F50M (too low with respect to the fitting line). The possible strength of a fully dense PSZ is $665 \mathrm{MPa}$.

The SEM micrographs of three polished and HF acidetched surfaces of the PSZ samples are shown in the right column of Fig. 5. Due to the abundance of porosity of these PSZ samples with the coarse grains of $50 \%$ or more, the grinding and polishing forces were greatly reduced to prevent grain pull-out. However, the grain pull-out was still occasionally found on the polished surfaces of F00 sample, resulting in a porosity over than that measured by Archimedes' method. The F100H sample [in Fig. 5(a)] has a uniform grain structure with the grain sizes of 20 to $50 \mu \mathrm{m}$ and closed porosity in the sizes 4 to $16 \mu \mathrm{m}$. The t-phase grains revealed by etching have sizes less than $0.1 \mu \mathrm{m}$. As the matrix containing coarse grains, the microstructure of the sintered PSZ appears as fully dense regions corresponding to the coarse grains added in the formulation. The large grains are angular and mostly associated with tiny cracks as the F75L shown in Fig. 5(b). Connected pores (or cracks) as large as $160 \mu \mathrm{m}$ were occasionally found associated with coarse $\mathrm{ZrO}_{2}$. In comparison, F00 [Fig. $5(\mathrm{c})]$, which is an extreme case and made of $100 \%$ coarse powder, has $36 \%$ porosity. The grains of $\mathrm{F} 00$ are weakly bonded, and the pores in irregular shape are interconnected. The porosity in all samples is randomly distributed and in an irregular shape in the matrix.

The fracture surfaces of above mentioned PSZ samples are also shown in the left column of Fig. 5. The surfaces can be distinguished into three types, either a 

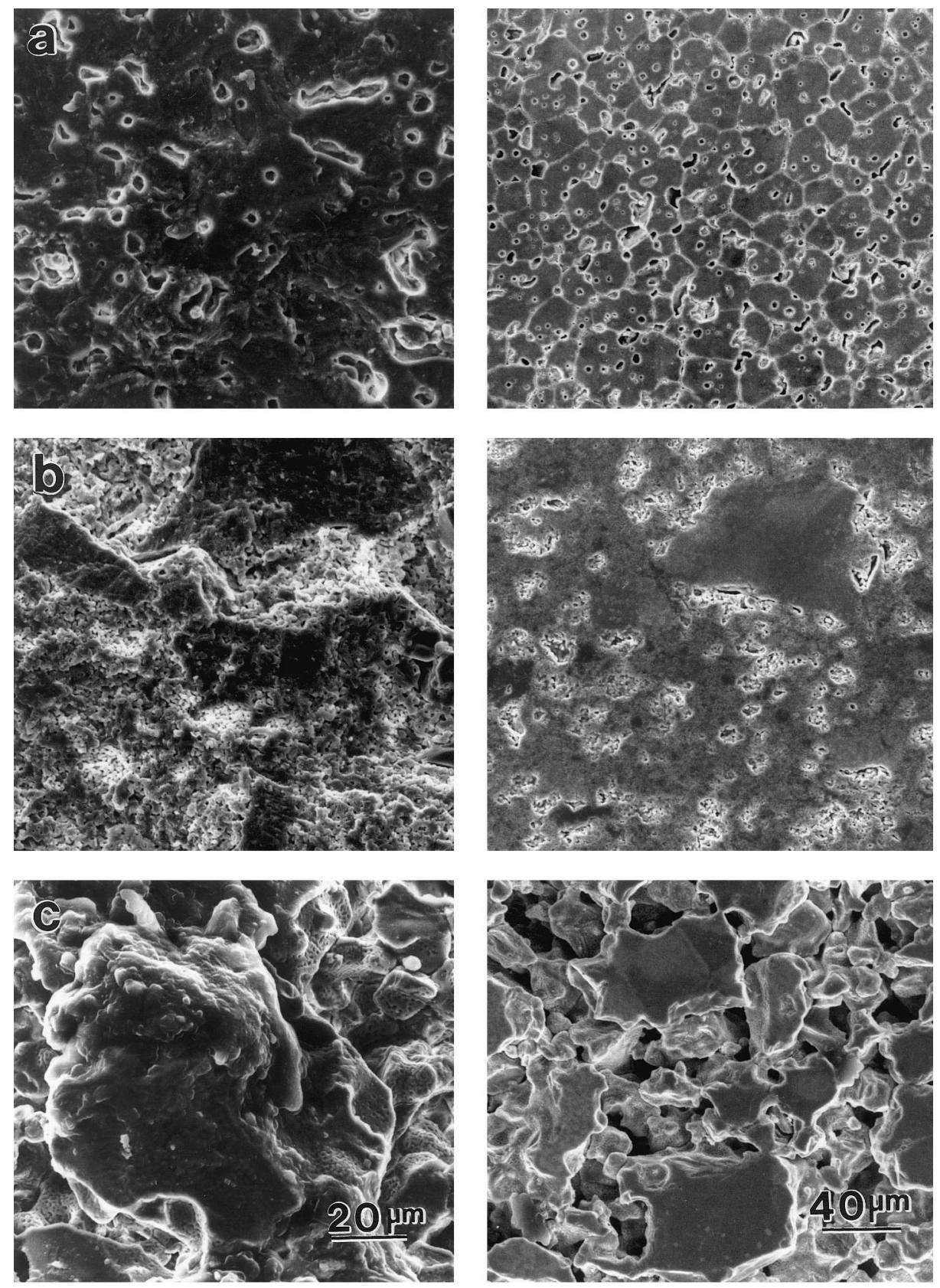

Fig. 5. SEM micrographs of the polished (right column) and fracture surfaces (left column) of the PSZ (a) F100H, (b) F75L, (c) F00 samples.

transgranular fracture, intergranular fracture, or a mixture. The transgranular fracture is dominate in two F100 and three F75 samples. The evidence observed is especially the fracturing of dense, large zirconia grains, as those in the micrographs of $\mathrm{F} 100 \mathrm{H}$ and F75L in Figs. 5(a) and (b). The coarse grains in the first fracturing type depict a sharp surface $^{1}$, while the second types samples have the fracture surfaces having cracks passing

\footnotetext{
${ }^{1}$ The surfaces of the coarse grains are mostly smooth, which is different from the grain surfaces exposed to sintering atmosphere [Fig. 5(c)]. Therefore, the flat regions in Fig. 5(b) are likely caused by the fracturing of coarse grain tested at room temperature.
}

along grain boundaries. Large grains with smooth surfaces in F25 or F00 specimens and no flat surface is observed [Fig. 5(c)].

Fig. 6 is the fracture toughness of 10 PSZ samples measured at room temperature. Four measurements of each sample are all plotted in the figure. The best toughness is the $5.4 \mathrm{MPa} \mathrm{m}^{1 / 2}$ of $\mathrm{F} 100 \mathrm{H}$. In literature, the toughness of $\mathrm{MgO}-\mathrm{PSZ}$ was reported ranging from $4.8^{14}$ to $13.5 \mathrm{MPa} \mathrm{m}{ }^{1 / 2}$. $^{3}$ Some MgO-PSZ samples also have an $R$-curve behavior. ${ }^{3}$ It is interesting to note that the data points in Fig. 6 cannot be formulated into one single curve, but rather separated into two curves in exponential function. Each behaves consistently with 


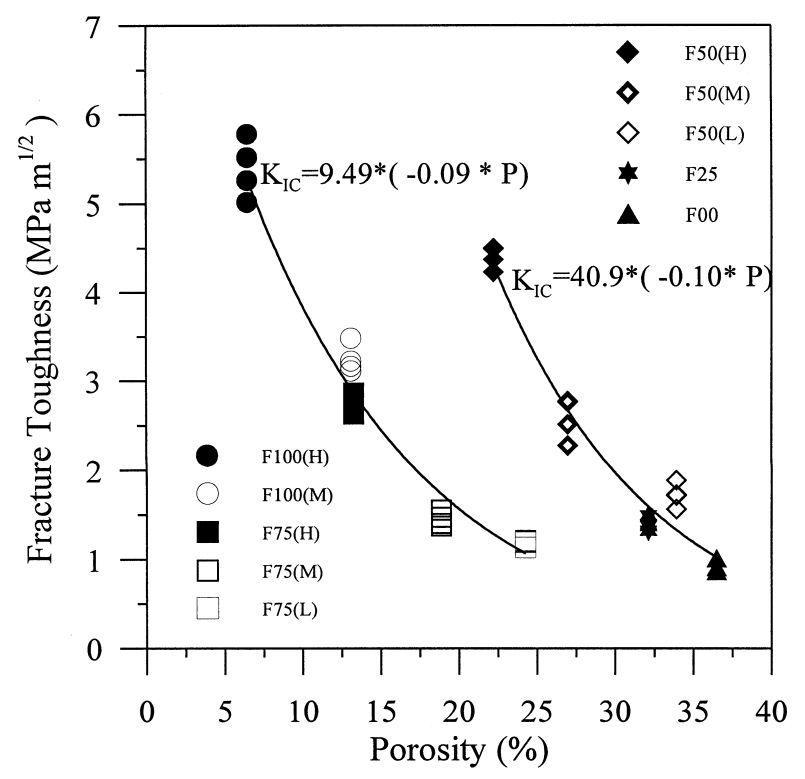

Fig. 6. Fracture toughness tested at room temperature plotted as a function of the porosity of PSZ. Note that the data are fitted into two curves.

respect to their formulation. The content of coarse grains is distinguished in an amount of $50 \%$, as shown in Fig. 6, implying that the factor(s) other than the porosity induced by the content of coarse grains should also control the fracture behavior of the PSZ.

\subsection{Thermal shock resistance of PSZ}

The residual strength $\left(\sigma_{\mathrm{r}}\right)$ of thermal shocked PSZ samples were measured and reported as a function of quenching temperature $(\Delta T)$, as shown in Fig. 7. The fitted curves in each sample reveal two fracturing behaviors. One appears to abruptly decrease in residual strength (type I) and the other decreases gradually (type II) when tested above a critical quenching temperature $\Delta T_{\mathrm{c}}$.

The type of fracture, the values of $\Delta T_{\mathrm{c}}$, the residual strength, and strength ratio $\left(\sigma_{\mathrm{r}} / \sigma_{\mathrm{f}}\right)$, are recorded and shown in Table 2. The results in the table show that F25 has the highest value $500^{\circ} \mathrm{C}$ in $\Delta T_{\mathrm{c}}$. The $\mathrm{F} 100 \mathrm{H}$ sample has the highest residual strength $(85 \mathrm{MPa})$ and $\mathrm{F} 50 \mathrm{M}$ has the greatest residual strength ratio $\left(\sigma_{\mathrm{r}} / \sigma_{\mathrm{f}}\right)$ of $77 \%$ among all PSZ, as shown in Fig. 7.

The fracture energy $\left(\gamma_{\mathrm{f}}\right)$ of each PSZ was calculated according to the Griffith equation:

$\gamma_{\mathrm{f}}=\frac{K_{\mathrm{IC}}^{2}\left(1-v^{2}\right)}{2 E}$

where $\gamma_{\mathrm{f}}$ is obtained from the values of $E, K_{\mathrm{IC}}$ and $v$, shown in the last column of Table 1 . The calculated fracture energy has the values from 4.6 to $64.2 \mathrm{~J} / \mathrm{m}^{2}$

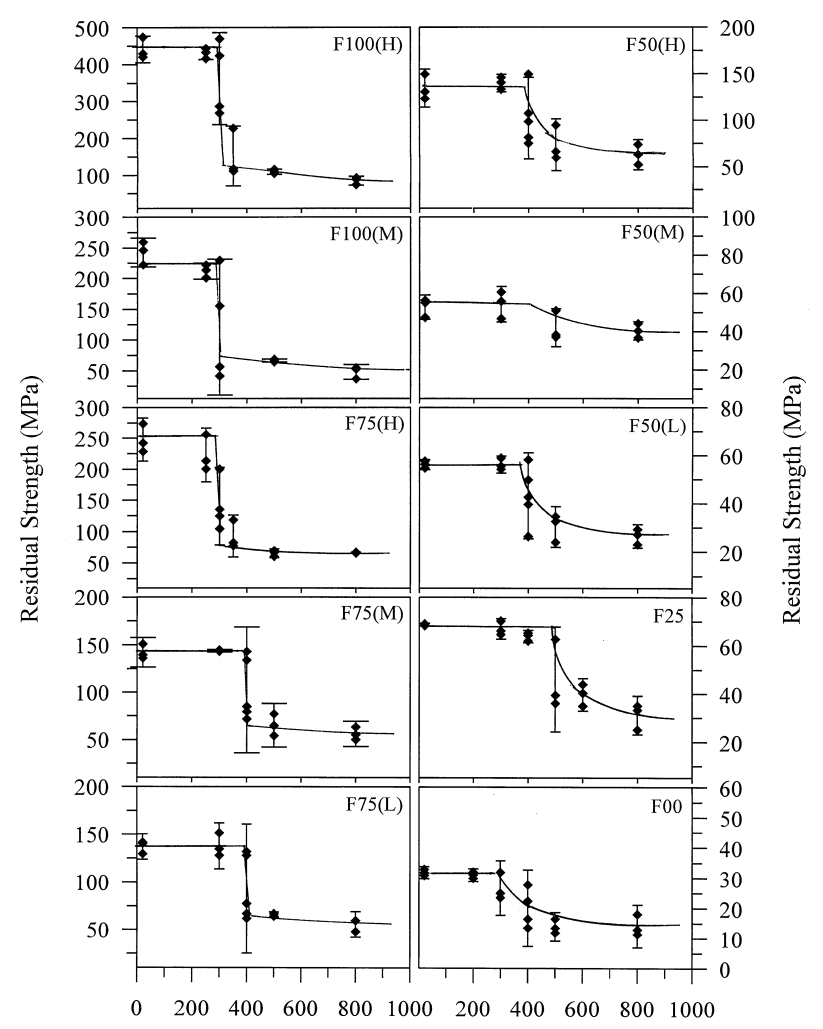

Fig. 7. Residual strength of PSZ plotted against critical quenching temperature difference $(\Delta T)$.

which is far less than the report (ca. $290 \mathrm{~J} / \mathrm{m}^{2}$ ) of the $\mathrm{Mg}-\mathrm{PSZ}^{15}$ annealed at $1000^{\circ} \mathrm{C}$.

\section{Discussion}

Several parameters of thermal shock resistance for the evaluation of ceramic materials have been proposed and reviewed in literature. ${ }^{16-19}$ A parameter, R, corresponds to the critical temperature, $\Delta T_{\mathrm{c}}$, which is thought to be the point that the thermal stress on the surface of a test piece equals to the fracture strength. In addition, $\mathrm{R}^{\prime \prime \prime}$, $\mathrm{R}^{\prime \prime \prime \prime}$ and the others are also used. These were considered in a relatively scale to reveal the resistance to the initiation or propagation of cracks, and to rank the relative capability of the thermal shock resistance of materials. The parameters are formulated as a combination of material properties, for instance Young's modulus, coefficient of thermal expansion (CTE), Poisson's ratio, and fracture strength.

Hasselman ${ }^{17,18}$ pointed out that pre-existing cracks and normalized quench temperature, $\Delta T / \Delta T_{\mathrm{c}}$, strongly influence crack growth behavior and residual strength after thermal shock. A ceramic material containing shorter cracks, $L_{0}$, less than a characteristic length, $L_{\mathrm{f}}$, shows a drastic drop in strength when the quench temperature $\Delta T$ is greater than $\Delta T_{\mathrm{c}}$. The released elastic 
Table 2

Fracture mode, critical quenching temperature difference, residual strength ratio, largest tolerable crack size and four thermal shock parameters of the PSZ samples ${ }^{\mathrm{a}}$

\begin{tabular}{lllllllllr}
\hline & Fracture mode & $\Delta T_{c}\left({ }^{\circ} \mathrm{C}\right)$ & $\sigma_{r}(\mathrm{MPa})$ & $\sigma_{r} / \sigma_{0}(\%)$ & $a_{t}(\mu \mathrm{m})$ & $R(\mathrm{~K})$ & $R^{\prime \prime \prime}\left(\times 10^{-16} / \mathrm{Pa}\right)$ & $R^{\prime \prime \prime \prime}(\mathrm{m})$ & $R_{s t}\left(\mathrm{~K} \mathrm{~m}{ }^{1 / 2}\right)$ \\
\hline F100H & Type I & 300 & 85 & 19 & 38 & 113 & 4.4 & 70.3 & 1.27 \\
F100M & Type I & 300 & 52 & 21 & 45 & 96 & 5.4 & 87.1 & 1.05 \\
F75H & Type I & 300 & 66 & 27 & 30 & 74 & 3.5 & 57.6 & 0.69 \\
F75M & Type I & 400 & 56 & 39 & 26 & 56 & 6.0 & 69.2 & 0.63 \\
F75L & Type I & 400 & 56 & 41 & 19 & 74 & 6.2 & 61.4 & 0.73 \\
F50H & Type II & 400 & 63 & 47 & 278 & 47 & 40.4 & 527 \\
F50M & Type II & 400 & 41 & 77 & 601 & 26 & 108 & 1.34 \\
F50L & Type II & 400 & 25 & 46 & 106 & 42 & 70 & 1142 \\
F25 & Type II & 500 & 31 & 46 & 252 & 49 & 30.5 & 1.10 \\
F00 & Type II & 300 & 15 & 36 & 121 & 27 & 32.2 & 475 & 1.16 \\
\hline
\end{tabular}

a Where $R=\sigma_{\mathrm{f}}(1-v) / E \alpha, R^{\prime \prime \prime}=\gamma / \sigma_{\mathrm{f}}^{2}(1-v), R^{\prime \prime \prime \prime}=\gamma E / \sigma_{\mathrm{f}}^{2}$, and $R_{\mathrm{st}}=\left(\gamma / \alpha^{2} E\right)^{1 / 2}$.

energy is adsorbed due to the extension of catastrophic cracks. But for the material with longer cracks, $L_{0}>L_{\mathrm{f}}$, the strength decreases gradually while testing under $\Delta T>\Delta T_{\mathrm{c}}$, implying that the cracks would propagate in a quasi-static manner. Two fracture modes of the retaining strength after thermal shock are categorized as type I or II, respectively.

\subsection{Porosity and characteristic defect length}

The ratio of the fine/coarse powder in PSZ formulation influences the sintering results in several aspects. The amount of the porosity and the pore dimension decreases as the content of the fine powder increases. As consequence, the material properties, including Young's modulus, shear modulus, especially the fracture strength and toughness, change accordingly as the state of the porosity varies.

The densest sample [F100H in Fig. 5(a)] has a uniform grain structure with closed pores in the sizes less than $15 \mathrm{~mm}$ located at the grain boundaries. No microcracks is found, except some fine precipitates of magnesium zirconate found at grain boundaries, identified by TEM and EDS. ${ }^{20,21}$ The t-phase precipitates revealed by etching have the sizes of $0.1 \mu \mathrm{m}$ and is smaller than that of the pores at grain boundaries.

The pores are the most predominant defects in the PSZ. Large zirconia grains are angular in sintered matrix and mostly surrounded with continuous pores, e.g. F75L in Fig. 5(b). These porous channels can be treated as the nucleation site of cracks and are frequently observed in the PSZ contained coarse grains. The size distribution of the pores is difficult to quantify from the ceramographic pictures. As a result, the defect size is hard to quantify too.

For simplification of the states of pores (defects), the greatest length $\left(a_{\mathrm{t}}\right)$ of defect is introduced. It represents a characteristic length of a nominal largest defect of which the PSZ can stand without catastrophic failure.
The $a_{\mathrm{t}}$ value can be determined from the toughness and strength of brittle PSZ specimens by Griffith relationship. Then, the $a_{\mathrm{t}}$ is

$a_{\mathrm{t}}=\frac{1}{\pi}\left(\frac{K_{\mathrm{IC}}}{1.12 \sigma_{\mathrm{f}}}\right)^{2}$

if the defect size is much smaller than the dimension $(W)$ of the test piece, i.e. a small $a_{\mathrm{t}} / W \cdot^{22}$ The calculated $a_{\mathrm{t}}$ values of each PSZ are shown in the sixth column of Table 2. It is noted that the PSZ with type II fracture mode has the tolerable defect length in the range of 106 to $601 \mu \mathrm{m}$, which is ca. 10 times higher than those of type I samples. The largest value $(600 \mu \mathrm{m})$ of $a_{\mathrm{t}}$ is shown for the F50M sample which has $50 \%$ coarse grains in the formulation and shows $27 \%$ porosity. It is the optimized condition that the test piece has the best tolerance to the testing condition. The residual strength $\left(\sigma_{\mathrm{r}} / \sigma_{\mathrm{f}}\right)$ of F50M is the best among $10 \mathrm{PSZ}$ samples.

The state of the defects would change, for instance the crack length increases during thermal shocking. The criteria of the crack extension either in Type I or II are controlled by the original crack length relative to characteristic length $\left(l_{\mathrm{f}}\right)$ and testing condition $\Delta T .{ }^{17} \mathrm{Knud}-$ sen reported ${ }^{23}$ that the fracture strength of ceramics is sensitive to structural defects and is controlled not only by grain size, also by the dimensions of pre-existing cracks. The porosity, a matter of important fracture origins, decreases the strength of the material.

The MgO-PSZ prepared in this study has the toughness ranging from 0.9 to $5.4 \mathrm{MPa} \mathrm{m} \mathrm{m}^{1 / 2}$. The reported $R$ curve behavior, ${ }^{3}$ which means the PSZ would increase in resistance to crack propagation as the length of the crack extends, is not observed in our PSZ samples. The toughness ${ }^{4}$ is strongly dependent on the size and the amount of the t-phase precipitate in PSZ. The transformation toughening seems not operate in the cases. The variation of toughness and fracture strength is controlled by the pre-existing defects (pores and cracks) of 
the PSZ, and in fact by the coarse/fine powder ratio in the formulation. But, these mechanical properties are not directly correlating to the thermal shocking behavior. The PSZ shows two groups of thermal shock resistance in Table 2. Type I with a denser matrix, and Type II with a high value of $\Delta T, \sigma_{\mathrm{r}} / \sigma_{0}$, and $a_{\mathrm{t}}$. The later (e.g. F50M and F25) is not necessarily performing a high toughness.

\subsection{Thermal shock resistance}

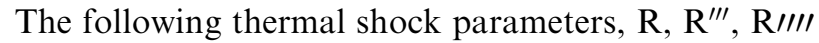
and $R_{\text {st }}$ are calculated according to the mechanical and material properties shown in Table $1^{17,18}$

$R=\sigma_{\mathrm{f}}(1-v) / E \alpha$

$R^{\prime \prime \prime}=\gamma / \sigma_{\mathrm{f}}^{2}(1-v)$

$R^{\prime \prime \prime \prime}=\gamma E / \sigma_{\mathrm{f}}^{2}$

and

$R_{\mathrm{st}}=\left(\gamma / \alpha^{2} E\right)^{1 / 2}$

As depicted in Table 2, a highest $R$ value $(113 \mathrm{~K})$ is performed on $\mathrm{F} 100 \mathrm{H}$, the highest $R^{\prime \prime \prime}$ and $R^{\prime \prime \prime \prime}$ $\left(108 \times 10^{-16} / \mathrm{Pa}\right.$ and $1142 \mathrm{~m}$, respectively) are achieved by $\mathrm{F} 50 \mathrm{M}$, and a best $\Delta T_{\mathrm{c}}\left(500^{\circ} \mathrm{C}\right)$ is noted on $\mathrm{F} 25$. These PSZ samples behaved very differently.

The best resistance to strength degradation $\left(\sigma_{\mathrm{r}} / \sigma_{0}\right)$ in the PSZ samples is F50M which performs a type II fracture. Four properties, $\Delta T_{\mathrm{c}}\left(400^{\circ} \mathrm{C}\right), R^{\prime \prime \prime}, R^{\prime \prime \prime \prime}$ and $\sigma_{\mathrm{r}} / \sigma_{0}(76 \%)$ of F50M are nearly the best among all PSZ samples. For the samples with a type II fracture, the best $\Delta T_{\mathrm{c}}$ is $500^{\circ} \mathrm{C}(\mathrm{F} 25)$. The $\mathrm{F} 25$ sample in fact has the highest $R$ value $(49 \mathrm{~K})$. For the samples with type I fracture, the $\mathrm{F} 100 \mathrm{H}$ has the greatest $R$ value and the highest residual strength $(85 \mathrm{MPa})$ among the tested PSZ, but its $\Delta T_{\mathrm{c}}$ is $300^{\circ} \mathrm{C}$ only.

It is difficult to address the relationship between thermal shock parameters with $\Delta T_{\mathrm{c}}$ and $\sigma_{\mathrm{r}} / \sigma_{0}$ without concerning the types of fracture. The samples with type I fracture mode have lower $\Delta T_{\mathrm{c}}, \sigma_{\mathrm{r}} / \sigma_{0}$ and $a_{\mathrm{t}}$ which do not appear to have any relationship with $R$ and $R_{\text {st }}$ as the parameters shown in Table 2. However, the residual strength ratio $\left(\sigma_{\mathrm{r}} / \sigma_{0}\right), R^{\prime \prime \prime}$ and $R^{\prime \prime \prime \prime}$ having a relationship can be shown as Fig. 8(a). The higher the $R^{\prime \prime \prime}$ and $R^{\prime \prime \prime \prime}$, the better the $\sigma_{\mathrm{r}} / \sigma_{0}$. PSZ samples with a porous character perform type II fracture and have a better thermal shock properties in $R^{\prime \prime \prime}$ and $R^{\prime \prime \prime \prime}$. The results appear that the $\sigma_{\mathrm{r}} / \sigma_{0}$ values are in general greater than $40 \%$ and better than the samples with type I fracture.

Fig. 8(b) depicts the dependence of two shock resistant parameters on the greatest length $a_{\mathrm{t}}$ of defect. A characteristic length of defects, $L_{\mathrm{f}}$, is noted which
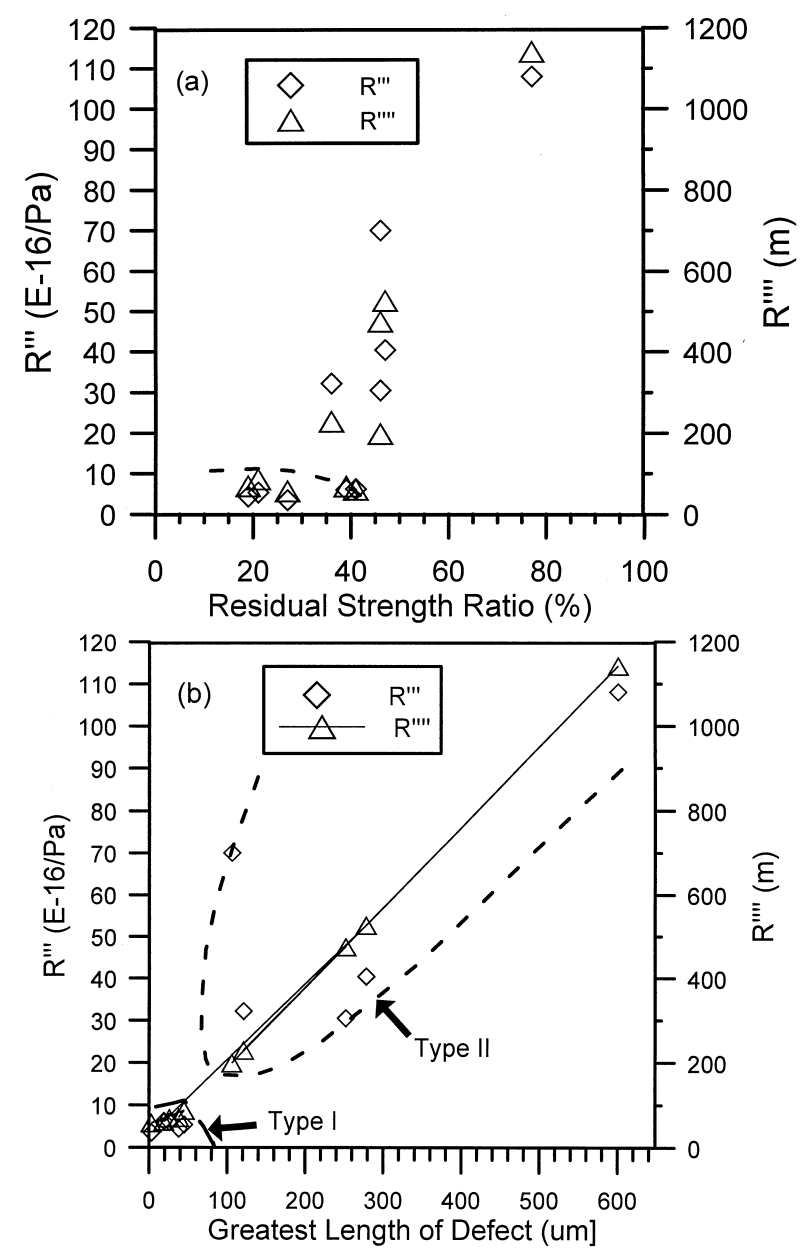

Fig. 8. Thermal shock parameters, $R^{\prime \prime \prime}$ and $R^{\prime \prime \prime \prime}$, plotted against (a) residual strength ratio and (b) greatest length of defect $a_{\mathrm{t}}$.

separates the samples to two groups with the boundary in Fig. 8(b). The value of $L_{\mathrm{f}}$ is in the size ca. $80 \mu \mathrm{m}$. The samples with either type I or II thermal shocking behavior can be distinguished by the boundary, the position of the characteristic length $L_{\mathrm{f}}$ of defect. That implies if the PSZ contains a defect in a size $L_{0}$ less than the characteristic length, $80 \mu \mathrm{m}$, the matrix undergoes a drastic drop in strength when the quench temperature is greater than $\Delta T_{\mathrm{c}}$. Type I shocking fracture takes place. But for the material with greater defects with a size longer than $80 \mu \mathrm{m}$, the strength decreases gradually when testing at $\Delta T$ higher than $\Delta T_{\mathrm{c}}$. The defects (pores) might extend in a quasi-static condition and result in greater residual strength ratio and $\Delta T_{\mathrm{c}}$.

\section{Conclusion}

The fraction of fine powder in the mixture is important for the sintering and thermal shock properties of PSZ materials. The properties of $10 \mathrm{Mg}-\mathrm{PSZ}$ with various microstructures and identical $\mathrm{t} / \mathrm{m}$ phase ratios were evaluated, and revealed the following. 
1. Young's modulus and shear modulus are not a function of the ratio of fine/coarse addition, but a relationship with the porosity of sintered PSZ. The highest values are $213 \mathrm{GPa}(E)$ and $142 \mathrm{GPa}(G)$ $(\mathrm{F} 100 \mathrm{H})$, respectively. The Poisson's ratio and linear thermal expansion coefficient of made PSZ are $0.2 \pm 0.05$ and $12.8 \pm 1.2 \times 10^{-6} / \mathrm{K}$, respectively, independent upon the porosity and the amount of fine powder.

2. The highest fracture strength is $441 \mathrm{MPa}$ of F100 (sintered at $1700^{\circ} \mathrm{C}$ for $4 \mathrm{~h}$ ) among all PSZ samples. The strength of the PSZ is an exponential function to the porosity of sintered PSZ.

3. There are two fracture mechanisms operating in the thermal shocked PSZ. Transgranular fracture occurs in the specimens with a fraction of fine powder more than 0.5 . The highest fracture toughness value is $5.4 \mathrm{MPa} \sqrt{\mathrm{m}}(\mathrm{F} 100 \mathrm{H})$; The other is intergranular fracture for the specimens with a fraction of fine powder less than 0.5. The resulting fracture toughness has the highest value, 4.4 MPa $\sqrt{\mathrm{m}}(\mathrm{F} 50 \mathrm{H})$. In each group, the fracture toughness decreases with an increase in porosity.

4. Three PSZs perform the best in thermal shock resistance. F50M has $\Delta T_{\mathrm{c}}=400^{\circ} C, R^{\prime \prime \prime}=108$, and a residual strength ratio of $77 \%$. F $100 \mathrm{H}$ has a best $R$ value $(113 \mathrm{~K})$ and a greatest residual strength (85 MPa) among the tested specimens. The highest $\Delta T_{\mathrm{c}}$ is $500^{\circ} \mathrm{C}$ (F25) which has the highest $R$ value among the samples with type II fracture.

5. Strong correlation between the largest tolerable defect size $a_{\mathrm{t}}$ to two thermal shock properties, $R^{\prime \prime \prime}$ and $R^{\prime \prime \prime \prime}$. The samples perform either type I or type II thermal shock behavior which can be differentiated by a characteristic length $L_{\mathrm{f}}$ of defect. The value of the $L_{\mathrm{f}}$ is determined in a size ca. $80 \mu \mathrm{m}$.

\section{Acknowledgements}

The authors gratefully acknowledge the support of the National Science Council (NSC86-2216-E-002-020) and Tjing Ling Industrial Research Institute (86-G-14) at the National Taiwan University.

\section{References}

1. Kienow, S., Refractory materials, Interceram., 1979, 28(3), 1-18 (Ceramic Monograph).
2. Bullard, R. L. and Cheng, P. C., Long term casting with zirconia nozzles. Iron \& Steelmaking, 1992, June, 19-26.

3. Heuer, A. H., Transformation toughening in $\mathrm{ZrO}_{2}$-containing ceramics. J. Am. Ceram. Soc., 1987, 70(10), 689-698.

4. Green, D. J., Hannink, R. H. J. and Swain, M. V. Transformation Toughening of Ceramics. CRC Press, Inc., 1989.

5. Ramaswamy, P., Narayana, B. H. and Vynatheya, S., Thermomechanical and microstructural evaluation of high tmeperature sintered (Mg, Mg-Ti)-PSZ. Ceram. Int., 1996, 22, 287-293.

6. Hannink, R. H. J. and Garvie, R. C., Subeutectoid aged Mg-PSZ alloy with enhanced thermal up-shock reistance. J. Mat. Sci., 1982, 17, 2637.

7. Lutz, H. E., Swain, V. M. and Claussen, N., Thermal shock behavior of duplex ceramics. J. Am. Ceram. Soc., 1991, 74(1), 1924.

8. Cotterell, B., Ong, S. W. and Qin, C., Thermal shock and size effects in castable refractories. J. Am. Ceram. Soc., 1995, 78(8), 2056-2064.

9. Schon, S., Prielipp, H., Janssen, R., Rodel, J. and Claussen, N., Effect of microstructural scale on thermal shock resistance of aluminum-reinforced alumina. J. Am. Ceram. Soc., 1994, 77(3), 701-704.

10. Wei, W. and Lin, Y. P., Processing character of $\mathrm{MgO}$-partial stabilized zirconia (PSZ) in size grading prepared by injection molding. J. Eur. Ceram. Soc., 1998, 18, 2107-2116.

11. Garvie, R. and Nicholson, P. S., Phase analysis in zirconia systems. J. Am. Ceram. Soc., 1972, 55(6), 303-305.

12. Wang, J., Rainforth, W. M., Wadsworth, I. and Stevens, R., The effects of notch width on the SENB toughness for oxide ceramics. J. Eur. Ceram. Soc., 1992, 10, 21-31.

13. Morrell, R., Handbook of Properties of Technical \& Engineering Ceramics, Part 1, An Introduction for the Engineer and Designer. National Physical Laboratory, London, 1985.

14. Nettleship, I. and Stevens, R., The effect of cooling rate on the phase transformations in Mg-PSZ. Br. Ceram, Trans, J., 1987, 86(6), 183-186.

15. Hughan, R. R. and Hannink, R. H. J., Precipitation during controlled cooling of magnesia-partially-stabilized zirconia. J. Am. Ceram. Soc., 1986, 69(7), 556-563.

16. Hasselman, D. P. H., Elastic energy at fracture and surface energy as design criteria for thermal shock. J. Am. Ceram. Soc., 1963, 46(11), 535-540.

17. Hasselman, D. P. H., In Ceramics in Severe Environments, ed. Kriegel and Palmour III. Plenum Press, New York, 1971, pp. 89103.

18. Hasselman, P. D. H., Figures-of-merit for the thermal stress resistance of high-temperature brittle materials: a review. Ceramurgia Int., 1978, 4(4), 147-150.

19. Arnold, M., Boccaccini, A. R. and Ondracek, G., Theoretical and experimental considerations on the thermal shock resistance of sintered glasses and ceramics using modelled microstructureproperty correlations. J. Mat. Sci., 1996, 31, 463-469.

20. Lin, Y. P., Master thesis, National Taiwan University, May 1997.

21. Farmer, S. C., Schoenlein, L. H. and Heuer, A. H., Precipitation of $\mathrm{Mg}_{2} \mathrm{Zr}_{5} \mathrm{O}_{12}$ in $\mathrm{MgO}$-partial stabilized $\mathrm{ZrO}_{2}$, Comm. Am. Ceram. Soc., 1985, July, C107-109.

22. Broek, D., Elemental Eng. Fract. Mechanics, 1984.

23. Knudsen, F. P., Dependence of mechanical strength of brittle polycrystalline specimens on porosity and grain size. J. Am Ceram. Soc., 1959, 42, 376. 